\title{
Loss of Chromosome 4p
}

National Cancer Institute

\section{Source}

National Cancer Institute. Loss of Chromosome 4p. NCI Thesaurus. Code C141398.

A cytogenic abnormality that refers to loss of all or part of the short arm of chromosome $4(4 p)$. 